\title{
Temperature Characteristics of Porous Portland Cement Concrete during the Hot Summer Session
}

\author{
Liqun Hu, Yangyang Li, Xiaolong Zou, Shaowen Du, Zhuangzhuang Liu, and Hao Huang \\ Key Laboratory of Special Area Highway Engineering of Ministry of Education, Chang'an University, Shaanxi, Xian 710064, China \\ Correspondence should be addressed to Liqun Hu; hlq@chd.edu.cn
}

Received 19 August 2016; Revised 18 January 2017; Accepted 18 January 2017; Published 9 February 2017

Academic Editor: Hossein Moayedi

Copyright (C) 2017 Liqun Hu et al. This is an open access article distributed under the Creative Commons Attribution License, which permits unrestricted use, distribution, and reproduction in any medium, provided the original work is properly cited.

\begin{abstract}
Pavement heats the near-surface air and affects the thermal comfort of the human body in hot summer. Because of a large amount of connected porosity of porous Portland cement concrete (PPCC), the thermal parameters of PPCC are much different from those of traditional Portland cement concrete (PCC). The temperature change characteristics of PPCC and the effects on surrounding environment are also different. A continuous 48-hour log of temperature of a PCC and five kinds of PPCC with different porosity were recorded in the open air in the hot summer. The air temperatures at different heights above concrete specimens were tested using self-made enclosed boxes to analyze the characteristics of near-surface air temperature. The output heat flux of different concrete specimens was calculated. The results show that the PPCC has higher temperature in the daytime and lower temperature in the nighttime and larger temperature gradient than the PCC. The air temperature above PPCC is lower than that of PCC after solar radiation going to zero at night. The total output heat flux of PPCC is slightly smaller in the daytime and significantly smaller at night than that of PCC. The results of tests and calculations indicate that PPCC contributes to the mitigation of heating effect of pavement on the near-surface air.
\end{abstract}

\section{Introduction}

Porous Portland cement concrete (PPCC), which is also known as pervious concrete, is a porous material, mixed, and molded by optimal percentages of water, cement, coarse aggregate, and additives. The range of air void content of PPCC is about $15 \%$ to $25 \%$ [1]. In recent years, with the improvement of the functional diversification requirements, engineers have paid more attention to the mechanical performance, water permeability, antisliding, and noise reduction of PPCC. Studies have shown that the PPCC not only could meet basic requirements of strength, but also have functions of breathability, permeability, antisliding, and noise reduction [2-6].

Pavement temperature periodically changes with the influence of solar radiation, air temperature, and wind. It is also significantly impacted by the properties of pavement materials. Therefore, temperature change of different pavements varies vastly even in the same environmental conditions. Li et al. found that the albedo of pavement surface had a momentous impact on the surface temperature.
The increase of albedo can sharply reduce the temperature of pavement surface in summer days [7]. Gui et al. analyzed the average maximum and minimum surface temperatures of pavement material with different thermophysical properties and found that the factor causing the highest decrease in the pavement maximum temperature is albedo, followed by thermal diffusivity, thermal conductivity, emissivity, and volumetric heat capacity, while the reduction in the pavement minimum temperature is most affected by emissivity, albedo, volumetric heat capacity, conductivity, and diffusivity in that order. Thermal conductivity, thermal diffusivity, and heat capacity have positive effects only on the pavement maximum temperature, but not on the minimum temperature with increasing values [8]. The surface and bottom temperatures of asphalt mixture slabs with different air void contents under steady state were analyzed. Hassn et al. found that, with the increase of air void content, the surface and bottom temperature of asphalt mixture slabs increased, and the maximum temperature of asphalt mixture slabs also increased [9]. Because PPCC have more air void content than traditional PCC, there are obvious differences between them. Studies 
by Haselbach et al. and Zhang et al. have shown that PPCC has rougher surface and lower albedo than traditional PCC pavement, so that PPCC can absorb more solar radiation $[10,11]$. Kevern et al. collected temperature data of pervious pavement and traditional pavement at different depths, respectively, and found that the temperature at middlelevel $(8 \mathrm{~cm}$ below the surface) in both concrete types was always higher than the air temperature. The temperature at middle-level in pervious pavement was higher than that of traditional pavement about $5^{\circ} \mathrm{C}$ during daytime. However, in the night, the temperature at middle-level in both pavements would decrease and reach similar temperature [12]. However, research on the temperature change characteristics of PPCC pavement is still limited and further study is needed.

The change of pavement temperature has an impact on surrounding environment and the near-surface air temperature and affects the thermal comfort of human body. For the sake of environmental protection, researchers pay more attention to this area and conduct more research in this area. Benrazavi et al. observed thermal performances of two kinds of polished granite, cement concrete, and asphalt concrete pavements in three different environments, namely, open space, near water, and under shade. They found that there was constant heat exchanging between surface and air. In addition, surface temperature of pavement had important effects on the change of near-surface air temperature [13]. Through analyzing the change characteristics of air temperature at $1.5 \mathrm{~m}$ above the surface of impervious asphalt and concrete pavements, pervious brick pavers, and grass, Guan et al. found that surface temperatures showed a positive and moderately strong correlation to air temperatures when surface temperatures increased. However, the air temperature above the different materials did not mimic the trend shown in surface temperatures [14]. Lin et al. also found that surface temperature of asphalt concrete pavement showed a positive correlation to air temperature in summer and thought that the heat output of pavement significantly impacted the air temperature and mean radiant temperature [15]. Rosenfeld et al. found that the local air temperature decreased by $0.6^{\circ} \mathrm{C}$ when the pavement-surface albedo increased from 0.05 to 0.30 [16]. In the aspect of the impact on ambient temperature of PPCC, the research of Qin and Hiller showed that pervious pavement could increase surface albedo and evaporation, which can promote the cool effect of pavement [17]. The research of Li et al. and Kevern et al. had shown that pervious concrete pavements store less energy than traditional pavements, which had a lower thermal effect on near-surface air and could alleviate urban heat island effect $[7,12]$. However, research in this area is still relatively insufficient.

PPCC have a smaller density and a good permeability because of $15 \%$ to $20 \%$ porosity. When used as a pavement material, PPCC is significantly different from PCC in thermal properties such as radiation, convection, and conduction due to rough surface and internal air. In order to understand the temperature change characteristics of PPCC and the impact of the temperature change on the surrounding environment, the data of surface and internal temperature of five kinds of PPCC and a PCC as reference at hot weather in summer were logged. Their impacts on the near-surface air temperature were studied by comparison of PPCC and PCC. The heat outputs of different types of concrete were calculated based on the model of pavement-surface energy balance. The results of the study would be helpful to further understand mutual influence law between PPCC and external environment.

\section{Materials and Methods}

2.1. Materials. Six types of concrete specimens were designed in this study, which were one kind of PCC and five kinds of PPCC. Different aggregates with single particle size were used to produce the PPCC. The dimensions of specimens were $30 \mathrm{~cm}$ (length) $\times 30 \mathrm{~cm}$ (width) $\times 15 \mathrm{~cm}$ (thickness). Parameters of those concrete are shown in Table 1. Albedo is the ratio of the reflected radiant flux to the incident solar radiant flux, which characterizes the ability of the pavement to absorb and reflect solar radiation [8]. Albedo and coefficient of thermal storage were calculated according to the references $[9,11,18]$.

2.2. Temperature Monitoring of Concrete. The temperature of pavement changes under the effect of environment factors. Because PPCC contains a certain amount of porosity, the temperature change characteristics of PPCC have great difference from PCC. In order to obtain the temperature change characteristics of PPCC, the data of temperatures on the surface, internal (at the depths of $5 \mathrm{~cm}$ and $10 \mathrm{~cm}$ ), and the bottom of specimens were logged. Six pits of $30 \mathrm{~cm}$ in length, $30 \mathrm{~cm}$ in width, and $15 \mathrm{~cm}$ in depth were dug in the natural clay soil ground. After compaction of soil at the bottom of the pits, graded crushed stone of $15 \mathrm{~cm}$ was filled and compacted as base course in the pits, and the six specimens were placed on the graded crushed stone layer to simulate pavement structures. The schematic figure of slabs specimens is presented in Figure 1(a).

Thermal resistance temperature sensors of PT100 with precision of $0.1^{\circ} \mathrm{C}$ were embedded in each specimen at the depths of $0 \mathrm{~cm}, 5 \mathrm{~cm}, 10 \mathrm{~cm}$, and $15 \mathrm{~cm}$ from the surface. DT85G produced by Datataker in Canada was applied as Data Collector, whose temperature data were automatically recorded in every $15 \mathrm{~min}$. In order to avoid the influence of the surrounding air on the test results, specimens were tightly wrapped with foam boards. A Weather Station was also placed closed to the specimens to log the data of weather conditions. The photograph of the experimental setup is shown in Figure 1(b).

2.3. Near-Surface Air Temperature Monitoring. The change of pavement temperature has impact on the near-surface air temperature and affects the human body's comfort. In order to study the influence of the heated pavement on the near-surface air temperature, the specimens were heated by exposing under the solar radiation from 9:00 to 15:15, and then the near-surface air temperature was investigated using five temperature sensors that were settled at the heights of $25 \mathrm{~cm}, 50 \mathrm{~cm}, 75 \mathrm{~cm}, 100 \mathrm{~cm}$, and $130 \mathrm{~cm}$ from the surface of specimen. Because the size of the specimens is small, it is difficult to test the influence of the specimens on the 
TABLE 1: Parameters of concrete.

\begin{tabular}{|c|c|c|c|c|c|c|c|c|}
\hline $\begin{array}{l}\text { Types of } \\
\text { concrete }\end{array}$ & $\begin{array}{l}\text { Particle } \\
\text { size } / \mathrm{mm}\end{array}$ & Porosity/\% & $\begin{array}{c}\text { Apparent } \\
\text { density } / \mathrm{kg} \cdot \mathrm{m}^{-3}\end{array}$ & Albedo & Emissivity & $\begin{array}{c}\text { Thermal } \\
\text { conductivity/W.m } \mathrm{m}^{-1} \text {. } \\
{ }^{\circ} \mathrm{C}^{-1}\end{array}$ & $\begin{array}{c}\text { Specific } \\
\text { heat } / \mathrm{J}^{\circ} \cdot \mathrm{kg}^{-1} \\
{ }^{\circ} \mathrm{C}^{-1}\end{array}$ & $\begin{array}{l}\text { Coefficient of thermal } \\
\text { storage/W } \cdot \mathrm{m}^{-2} \cdot{ }^{\circ} \mathrm{C}^{-1}\end{array}$ \\
\hline $\mathrm{PCC}_{0.075-16.0}$ & $0.075-16.0$ & 0.8 & 2100 & 0.4320 & 0.96 & $1.40[9,19]$ & $1050[9,18]$ & 14.99 \\
\hline $\mathrm{PPCC}_{2.36-4.75}$ & $2.36-4.75$ & 15.1 & 2048 & 0.3557 & 0.95 & 1.28 & 920 & 13.25 \\
\hline $\mathrm{PPCC}_{4.75-9.50}$ & $4.75-9.50$ & 18.2 & 1974 & 0.3401 & 0.94 & 1.26 & 900 & 12.77 \\
\hline $\mathrm{PPCC}_{9.50-13.2}$ & $9.50-13.2$ & 20.1 & 1928 & 0.3305 & 0.94 & 1.23 & 870 & 12.26 \\
\hline $\mathrm{PPCC}_{13.2-16.0}$ & $13.2-16.0$ & 21.8 & 1887 & 0.3219 & 0.93 & 1.22 & 860 & 12.01 \\
\hline $\mathrm{PPCC}_{16.0-19.0}$ & $16.0-19.0$ & 24.9 & 1812 & 0.3063 & 0.92 & 1.20 & 840 & 11.53 \\
\hline
\end{tabular}

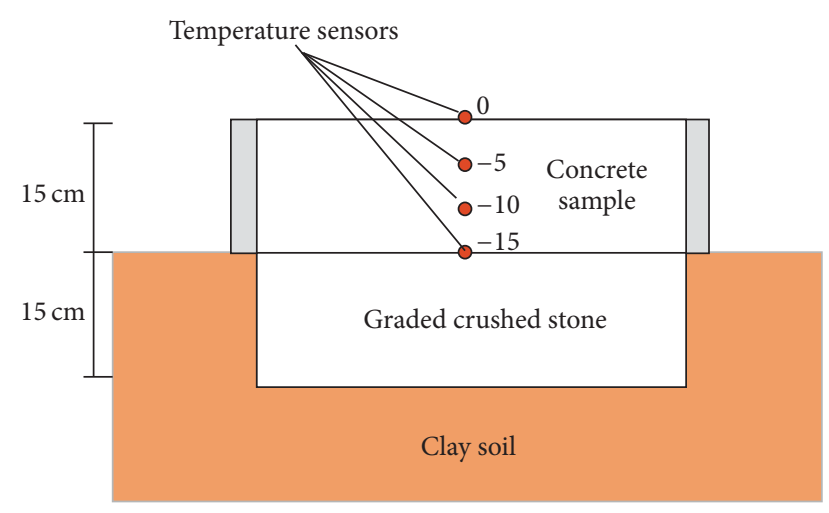

(a)

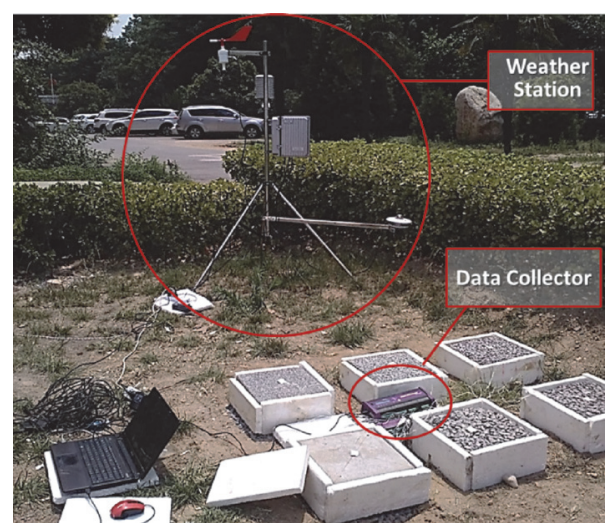

(b)

FIGURE 1: Temperature monitoring system: (a) schematic figure of slabs specimens; (b) photograph of the experimental setup.

near-surface air temperature. In addition, the near-surface air temperature is easily affected by the surrounding air temperature. In order to enlarge the impact of the heated specimens on the near-surface air temperature and avoid the influence of the surrounding air, foam board boxes of $150 \mathrm{~cm}$ (height) $\times 30 \mathrm{~cm}$ (length) $\times 30 \mathrm{~cm}$ (width) were placed above the specimens. The schematic figure of near-surface air temperature monitoring device is shown in Figure 2(a). The temperature data were automatically logged by Datataker in every $15 \mathrm{~min}$. The photograph of near-surface air temperature monitoring device is shown in Figure 2(b).

2.4. Calculation of Heat Output of Pavement. The influence of pavements on surrounding environment is closely related to the heat input and output of pavements. To further illustrate the effect of different concrete specimens on surrounding environment, the characteristics of heat output of different concrete were calculated and analyzed according to the changes of the surface temperature of the specimens.

Figure 3 shows the model of pavement-surface energy balance. Pavement-surface energy balance equation is shown as follows:

$$
H_{\Delta}=\left(q_{s}-H_{r}\right)+H_{c}+H_{l}+H_{\text {cond }},
$$

where $H_{\Delta}$ is the change of pavement energy; $q_{s}$ is the solar radiation; $H_{r}$ is the short-wave solar radiation reflected by road surface; $H_{c}$ is the convective heat between surface and air; $H_{l}$ is the long-wave net radiation; and $H_{\text {cond }}$ is the pavement-surface-downward heat conduction.

Heat flux from pavement surface to outside air was calculated, which included the convective heat between pavement surface and the outside air, long-wave net radiation, and the short-wave solar radiation reflected by road surface. The total output heat flux, which is $H_{o}$, is the sum of the three types of heat flux. $H_{c}, H_{l}, H_{r}[15]$, and $H_{o}$ are calculated as follows:

$$
\begin{aligned}
& H_{c}=h_{\infty}\left(T_{s}-T_{\infty}\right), \\
& H_{l}=\Psi_{\text {sky }} \varepsilon \sigma\left(T_{s}^{4}-T_{\text {sky }}{ }^{4}\right), \\
& H_{r}=\tilde{a} \times q_{s}, \\
& H_{o}=H_{c}+H_{l}+H_{r},
\end{aligned}
$$

where $h_{\infty}$ is the convective heat coefficient of air, $h_{\infty}=$ $0.664 k_{\infty}{ }^{\infty} r_{\infty}{ }^{0.3} v_{\infty}{ }^{-0.5} L^{-0.5} U_{\infty}{ }^{0.5}[8]$, and $k_{\infty}$ is the thermal conductivity of air; $\operatorname{Pr}_{\infty}$ is the Prandtl number; $v_{\infty}$ is the kinematic viscosity; $L$ is the length; $U_{\infty}$ is the wind speed; $T_{s}$ is the temperature of surface; $\Psi_{\text {sky }}$ is the sky view factor; the value is set to be one because the pavement structure is completely open to the sky. $\varepsilon$ is the infrared emissivity of the surface, $\sigma$ is the Stefan-Boltzmann constant, $5.67 \times$ $10^{-8} \mathrm{Wm}^{-2} \mathrm{~K}^{-4} ; T_{\text {sky }}$ is the sky temperature, which can be estimated using $T_{\text {sky }}=T_{\infty}\left(0.004 T_{\text {dew }}+0.8\right)^{0.25}[8] ; T_{\infty}$ is the atmospheric dry-bulb temperature; $T_{\text {dew }}$ is the dew point, unit in $\mathrm{K} ; \tilde{a}$ is the albedo. 


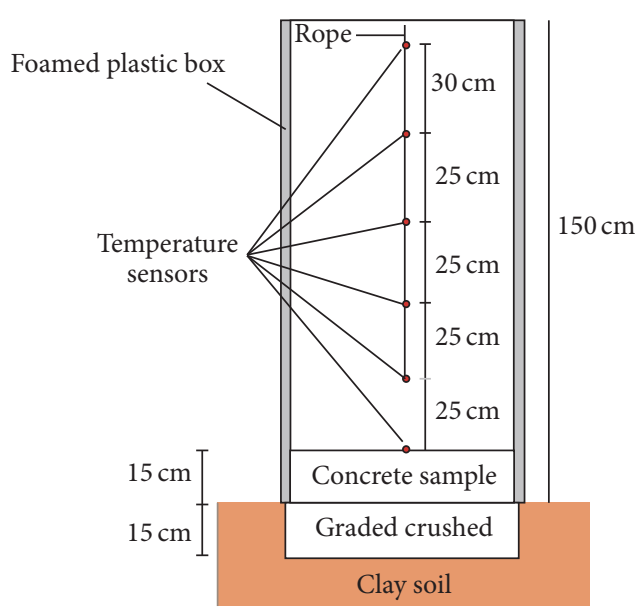

(a)

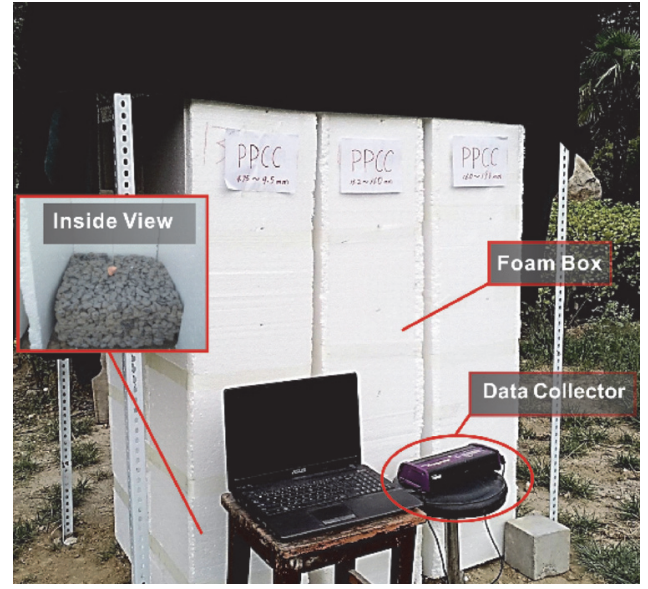

(b)

FIGURE 2: Near-surface air temperature monitoring device: (a) schematic figure of near-surface air temperature monitoring device; (b) photograph of near-surface air temperature monitoring device.

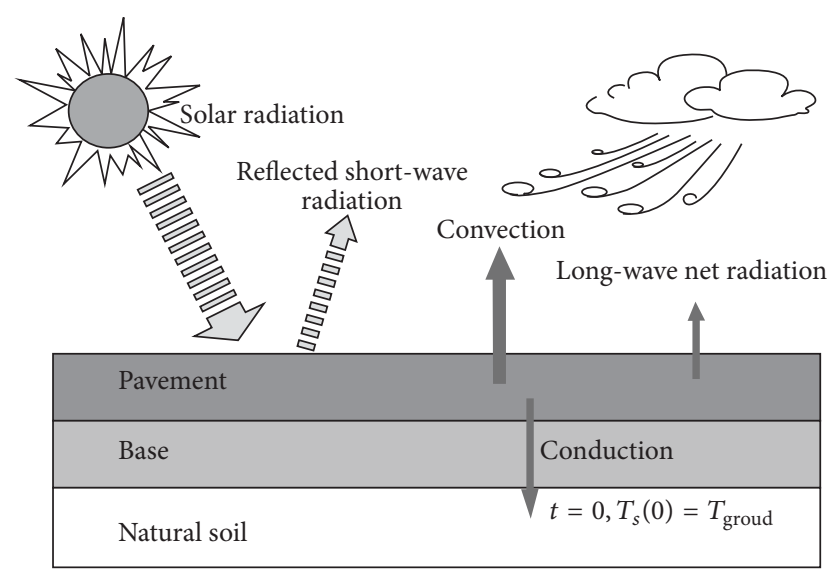

Figure 3: The model of pavement-surface energy balance.

\section{Results and Discussion}

3.1. Temperature Change Characteristics of Concrete. Data of air temperature and solar radiation at the test site were logged continuously from 9:15 on June 18, 2016, to 9:15 on June 20,2016 , by Weather Station. The curves of air temperature and solar radiation are shown in Figure 4. The weather at the test site on June 18, 2016 was mainly cloudy. The maximum temperature of $36.5^{\circ} \mathrm{C}$ was reached at 15:30 and the largest solar radiation of $881 \mathrm{~W} / \mathrm{m}^{2}$ was reached at 12:45. Solar radiation continued until 19:30. The weather at the test site on June 19, 2016 was mainly sunny. The maximum temperature of $39.2^{\circ} \mathrm{C}$ was reached at 16:30 and the largest solar radiation of $979 \mathrm{~W} / \mathrm{m}^{2}$ was reached at 13:00. Solar radiation continued until 19:45. The peaks of temperature were reached later and then the peaks of solar radiation were reached. The peaks of the temperature and the solar radiation on June 19 were higher than those on June 18. The solar radiation on June 19 had a longer duration.

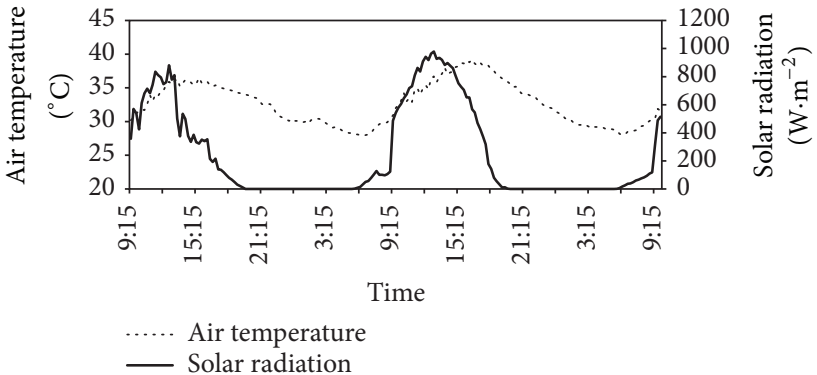

FIGURE 4: Air temperature and solar radiation.

Temperature data of six types of concrete at different depths were logged from 9:15 on June 18, 2016, to 9:15 on June 20, 2016, by the Data Collector. The curves of temperature are shown in Figure 5. As presented in Figure 5, the curves at different depths fluctuated similarly as the curves of air temperature. The temperature of each concrete on surface (depths of $0 \mathrm{~cm}$ ) changed basically synchronously with the air temperature. Both of them reached the maximum at about 15:00 and reached the minimum at around 5:00 in the next day. However, the changes of temperature at the depths of $-5 \mathrm{~cm},-10 \mathrm{~cm}$, and $-15 \mathrm{~cm}$ lagged behind the changes of air temperature and the lag obviously enlarged with the depth. In addition, the lag of temperature of PCC at each measuring point was more significant than that of PPCC. The curves of temperature of PPCC fluctuated more drastically than those of PCC.

PPCC has a smaller specific heat capacity due to its porous structure, and the specific heat capacity of PPCC decreases with the increase of porosity $[9,18,20]$. The specific heat capacity of PPCC approximately is lower by $12.4 \%$ to $20.0 \%$ than that of PCC. Specific heat capacity has an influence on heat absorption and release for materials, thereby affecting the temperature changes of materials. Moreover, the coefficient of thermal storage has a similar effect on materials. The 


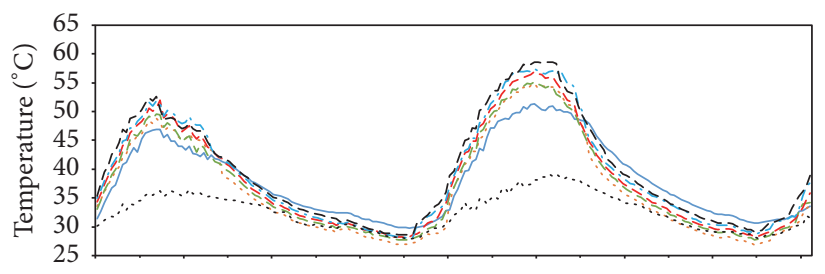

(a)

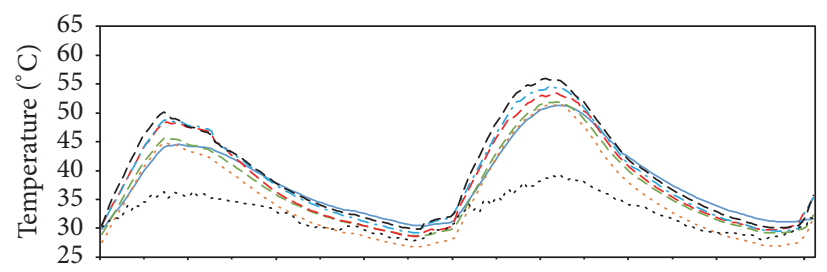

(b)

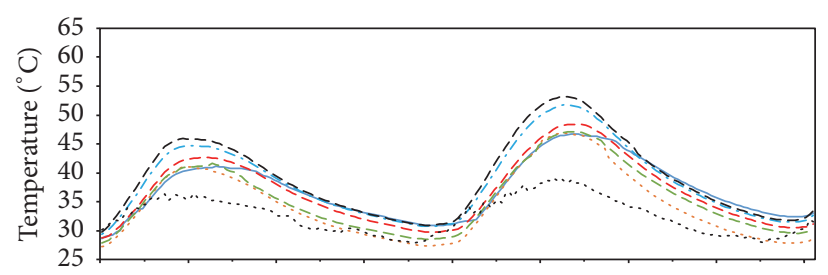

(c)

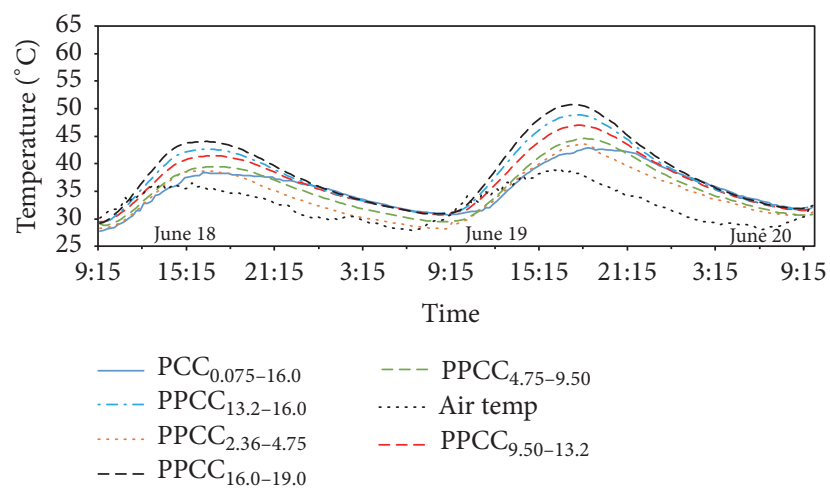

(d)

FIGURE 5: Temperature values of concrete at different depths: (a) $0 \mathrm{~cm}$; (b) $-5 \mathrm{~cm}$; (c) $-10 \mathrm{~cm}$; and (d) $-15 \mathrm{~cm}$.

temperature of material with smaller specific heat capacity and coefficient of thermal storage is more susceptible to external environment, which is the reason for the fluctuation of temperature changes of PPCC that is significantly greater than that of PCC under the same test conditions.

The comparisons of different concrete specimens at different depths for daytime maximum temperature and nighttime minimum temperature are shown in Figures 6(a) and 6(b), respectively. It can be seen that the temperatures of PPCC were basically higher than the temperatures of PCC at corresponding positions during daytime. In the night, the minimum temperatures of PPCC were lower than the minimum temperatures of PCC at corresponding positions. As shown in Figure 6, the temperature changes of different PPCC related to the particle sizes of aggregates. The PPCC with the larger particle size of aggregate had the relatively higher maximum temperature and minimum temperature.

Solar radiation is the main factor to promote cement concrete surface warming. Generally, the higher the albedo of surface is, the more the solar radiation is reflected to reduce rising of temperature caused by absorption of solar radiation. Five kinds of PPCC contain a large number of coarse aggregates and the surface texture is rough after forming. The albedo of PPCC is smaller by $17.7 \%$ to $29.1 \%$ than that of PCC, with the albedo of PPCC increasing with the increase of aggregate particle size. In addition, the surface area of the PPCC increases because of the uneven surface, so that PPCC has greater acceptance area for solar radiation. At the same time, PPCC has a smaller specific heat capacity and coefficient of thermal storage, which make the heating rate of PPCC faster and the maximum temperature of PPCC higher than that of PCC in the daytime. The temperatures of PPCC lower than that of PCC during nighttime are closely related to smaller specific heat capacity and coefficient of thermal storage of PPCC, and a lot of interconnected pores of PPCC contribute to the rapid release of heat.

The vertical temperature difference in the concrete due to the effect of the external environment is called temperature gradient. The temperature gradient can be calculated according to the following:

$$
\text { Temperature gradient }=\frac{\left(T_{\text {sur }}-T_{\text {bot }}\right)}{H},
$$

where $T_{\text {sur }}=$ the temperature on the surface of specimen, ${ }^{\circ} \mathrm{C}$; $T_{\text {bot }}=$ the temperature at the bottom of specimen, and ${ }^{\circ} \mathrm{C} ; \mathrm{H}$ $=$ the thickness of specimen, $\mathrm{cm}$.

The temperature gradients of concrete were calculated by the maximum temperature of surface in the daytime and the minimum temperature in the nighttime. The temperature gradients of different concrete are shown in Figure 7.

It can be seen from Figure 7 that the temperature gradients of the PPCC were 0.7 to $1.2^{\circ} \mathrm{C} / \mathrm{cm}$ when the surfaces reached the maximum temperature during the day. The temperature gradient increased with the particle size of aggregate. The temperature gradient of PCC was $0.7^{\circ} \mathrm{C} / \mathrm{cm}$ and significantly less than that of PPCC. When the surface temperature of the specimens respectively reached the minimum temperature at night, the temperature gradient of PCC was smaller than those of 5 kinds of PPCC. But the temperature gradient at night is much smaller than that during the day.

Thermal conductivity is an important parameter to measure internal heat transfer capability of objects. PPCC contains more amount of coarse aggregate than PCC does. The point contacts between aggregate particles weaken the heat conduction leading to thermal conductivity of PPCC being less than that of the compacted PCC. The thermal conductivity of PPCC is lower by $8.5 \%$ to $14.3 \%$ than that of PCC in this research and the thermal conductivity of PPCC decreases with the increase of aggregate particle size. The smaller the thermal conductivity is, the greater the temperature difference between surface and internal different positions usually is. Therefore, small thermal conductivity in 


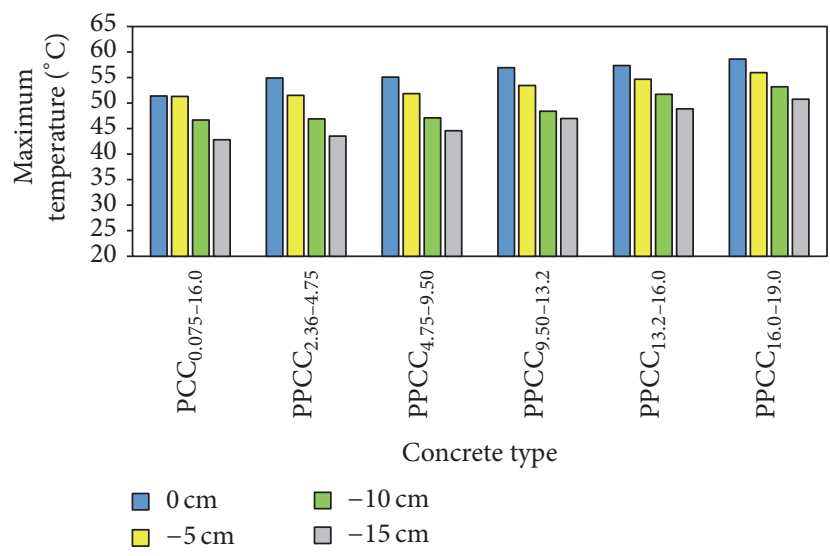

(a)

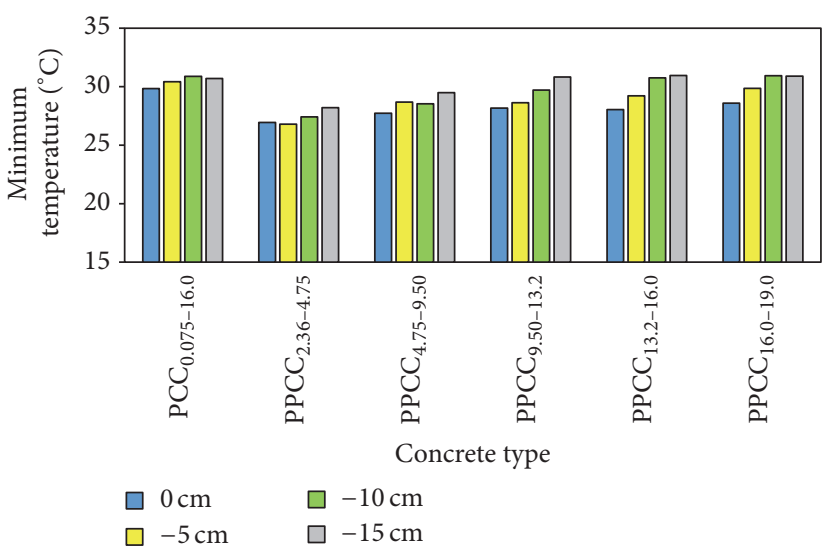

(b)

Figure 6: Maximum temperature and minimum temperature of different concrete: (a) maximum temperature in the daytime; (b) minimum temperature in the nighttime.

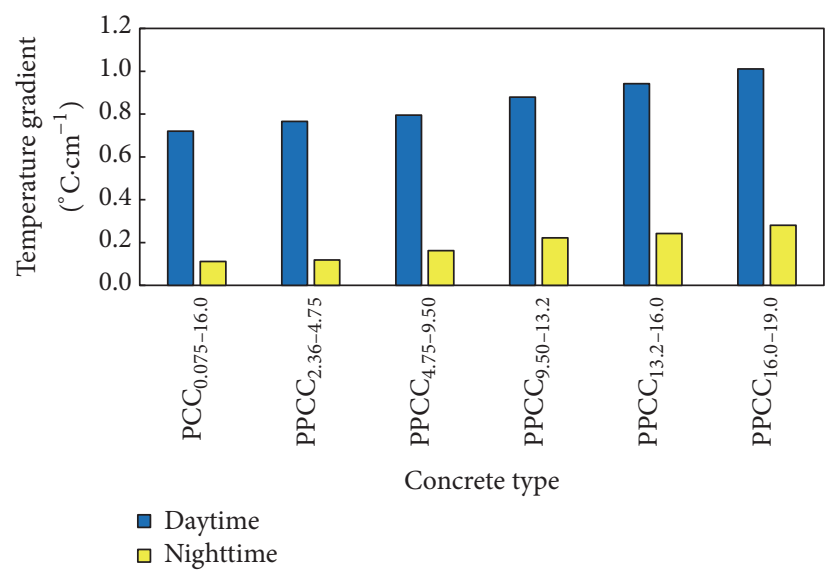

FIGURE 7: The temperature gradients of different concrete.

PPCC increases the difference between surface temperature and bottom temperature. This is the main reason for the temperature gradient of PPCC being greater than that of PCC.

\subsection{Analysis of Characteristics on Change of Near-Surface Air} Temperature of Concrete. The near-surface air temperatures were tested on July 17, 2016 and data of air temperature at $25 \mathrm{~cm}, 50 \mathrm{~cm}, 75 \mathrm{~cm}, 100 \mathrm{~cm}$, and $130 \mathrm{~cm}$ above surface of specimens started to be logged at 15:45. The air temperature was $33.9^{\circ} \mathrm{C}$ at $15: 45$. The initial surface temperature of $\mathrm{PCC}_{0.075-16.0}, \mathrm{PPCC}_{2.36-4.75}, \mathrm{PPCC}_{4.75-9.50}, \mathrm{PPCC}_{9.50-13.2}$, $\mathrm{PPCC}_{13.2-16.0}$, and $\mathrm{PPCC}_{16.0-19.0}$ was $40.5^{\circ} \mathrm{C}, 41.7^{\circ} \mathrm{C}, 42.0^{\circ} \mathrm{C}$, $42.7^{\circ} \mathrm{C}, 43.0^{\circ} \mathrm{C}$, and $42.5^{\circ} \mathrm{C}$, respectively. The curves of nearsurface air temperature and surface temperature are shown in Figure 8.

From Figure 8, it can be seen that the hot specimens started to heat the air in box after specimens were covered by foamed plastic box. The air temperature at $25 \mathrm{~cm}, 50 \mathrm{~cm}$, $75 \mathrm{~cm}, 100 \mathrm{~cm}$, and $130 \mathrm{~cm}$ above specimen surface increased with time firstly and reached the peaks about at $60 \mathrm{~min}$ after the start of test. Then, the air temperatures at the different heights dropped slowly after the peaks and levelled off over time.

The surface temperature and thermal storage of specimen in the box are the key factors for influence on the nearsurface air temperature. Because solar radiation was blocked by the box, the temperature of specimen surface decreased gradually. Within initial $240 \mathrm{~min}$, the surface temperature of the PPCC was higher than the surface temperature of PCC, and air temperatures at the different heights above PPCC in the boxes were higher than that of PCC in the corresponding positions. The air temperature in each box reached the peak at 16:45 (60 min after test beginning). The near-surface air temperatures above different concrete are presented in Figure 9. It can be seen from Figure 9(a) that the air temperatures at different position above PPCC specimens were higher than those above the PCC specimen in the corresponding position. Compared with different PPCC, the near-surface air temperatures at corresponding positions increased with the particle size of aggregates. In addition, the near-surface air temperature decreased with height.

After about 240 min of test beginning, the surface temperature of PPCC specimens was lower than that of PCC gradually, which is due to specific heat capacity and coefficient of thermal storage of PPCC is small compared with the PCC and PPCC is easier to cool when it loses the heat source of solar radiation. From Figure 9(b), it can be seen that the air temperatures at different positions above five kinds of PPCC specimens were lower than those above PCC specimen at the corresponding position at 6:45.

The results of tests indicated that PPCC increases the near-surface air temperature during a short time after solar radiation being shaded in hot summer; however, the situation conversely changes over time. Because the capacity of heat releasing of PPCC is less than that of PCC, the air temperature above PPCC is lower than that above PCC after the peak of air temperature. 


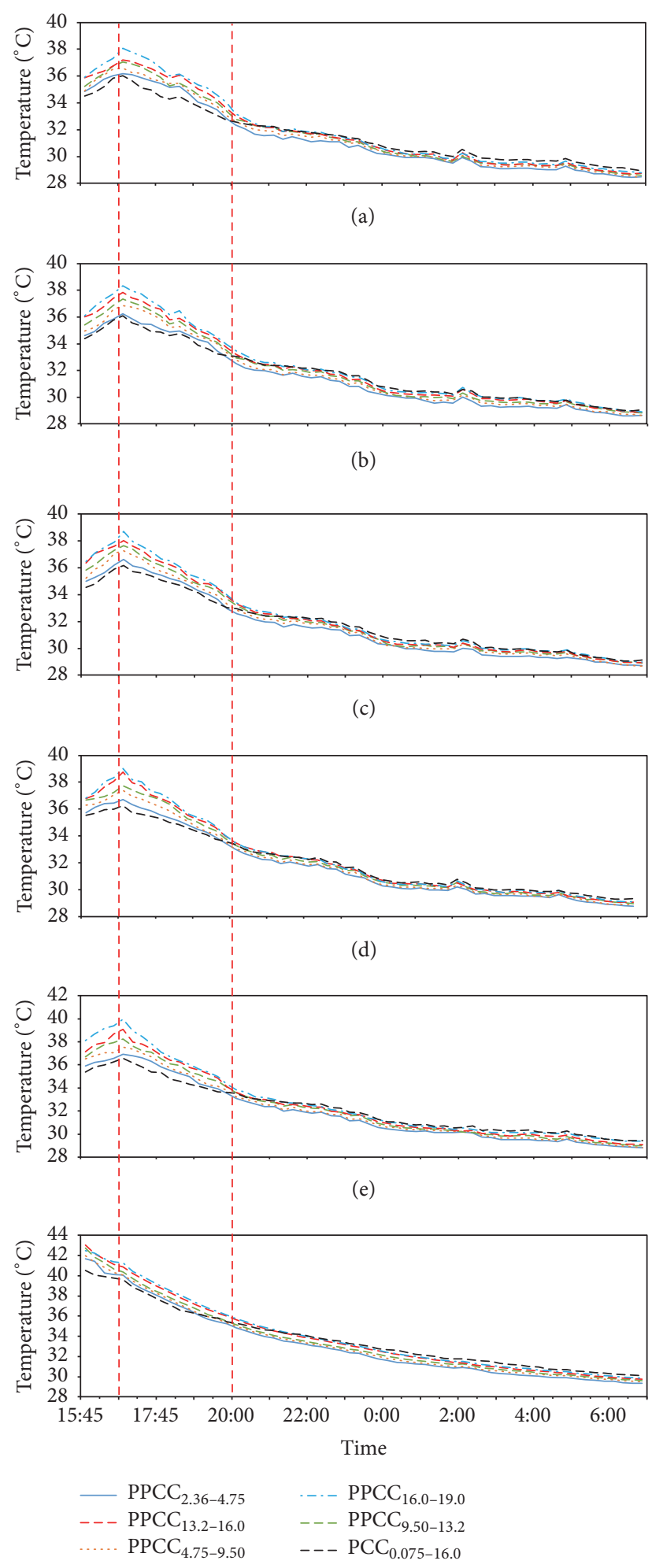

(f)

Figure 8: The curves of surface temperature and near-surface air temperature: (a) $130 \mathrm{~cm}$; (b) $100 \mathrm{~cm}$; (c) $75 \mathrm{~cm}$; (d) $50 \mathrm{~cm}$; (e) $25 \mathrm{~cm}$; (f) $0 \mathrm{~cm}$.

3.3. Heat Output Analysis. The temperature of pavement is influenced by environmental conditions. At the same time, the heat output from the pavement impacts the air temperature, especially near-surface air temperature. There are three types of heat output from pavement: the first is convective heat flux, the second is reflected short-wave solar radiation heat flux, and the last is long-wave net radiation heat flux. Those three type heat output values of different kinds of concrete within $48 \mathrm{~h}$ are calculated according to (2)-(4). The calculation results are shown in Figures 10(a), 10(b), and 10(c), respectively.

As shown in Figure 10, in the daytime, the convective heat and long-wave net radiation of PPCC are higher than those of PCC. The reflected short-wave solar radiation of PPCC is lower than that of PCC. The heat flux has obvious difference between different PPCC. The convective heat and long-wave net radiation increase and the reflected short-wave solar radiation decreases with the increase of particles size of aggregate. In addition, because of the impact of the wind change in the daytime, the curves of convective heat have obvious sawtooth wave.

The convective heat and long-wave net radiation are mainly related to the surface temperature of specimens. Therefore, the sequence of convective heat and long-wave net radiation of different PPCC are basically in accordance with surface temperature of PPCC, respectively. Reflected shortwave solar radiation is mainly associated with the albedo of material. Surface temperature of PCC is lower due to its higher albedo. However, more solar radiation will be reflected to the surrounding air by PCC at the same time, which is the reason that the short-wave solar radiation of PCC is significantly higher than that of PPCC. The calculation results also show that the heat output of reflected short-wave solar radiation is much higher than the heat output of convective heat and long-wave net radiation.

At night, because of solar radiation disappearing, the reflected short-wave solar radiation values of several concrete types are all zero. Therefore, the surface temperature of PCC specimens is higher than those of five kinds of PPCC gradually. And the change trends of the convective heat and long-wave net radiation of several concrete types are contrary to those in the daytime. That is, the convective heat and longwave net radiation of five kinds of PPCC are lower than those of PCC. And the coarser aggregate particles size of PPCC is, the larger corresponding convective heat and long-wave net radiation are.

The impacts of concrete on surrounding air depend on its total output heat flux. The total output value of heat flux is the sum of the convective heat flux, the reflected short-wave solar radiation, and the long-wave net radiation [15]. The curve of total output heat flux versus time is shown in Figure 11.

It can be seen from Figure 11 that, in the daytime, the total output heat flux of PCC is slightly larger than those of PPCC. For example, the max of total output heat flux of $\mathrm{PCC}_{0.075-16.0}$, PPCC $_{2.36-4.75}$, PPCC $_{4.75-9.50}$, PPCC $_{9.50-13.2}$, PPCC $_{13.2-16.0}$, and PPCC $_{16.0-19.0}$ on June 19 is 618.6, 591.8, 590.1, 603.1, 616.9, and $610.8 \mathrm{~W} / \mathrm{m}^{2}$, respectively. The average of total output heat flux of those six concrete types is $320.9,295.6,292.6,303.2$, 311.6, and $317.6 \mathrm{~W} / \mathrm{m}^{2}$, respectively. The calculations show that total output heat flux of the six concrete types and the effect on the 


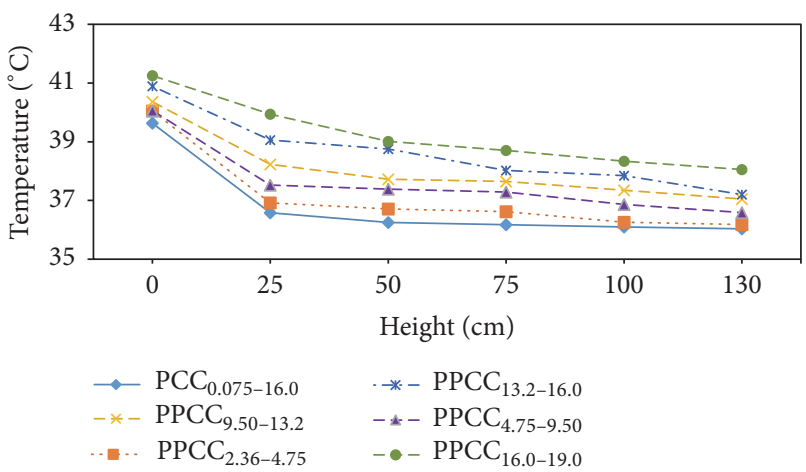

(a)

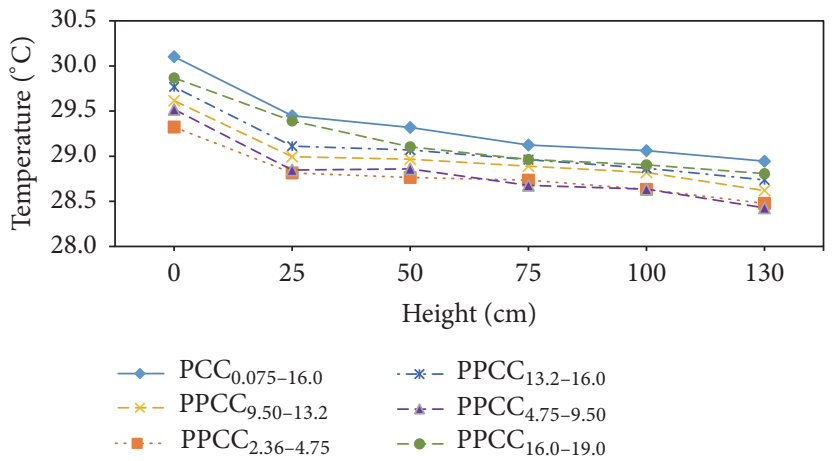

(b)

FIGURE 9: The near-surface air temperature above different concrete: (a) 16:45; (b) 6:45.

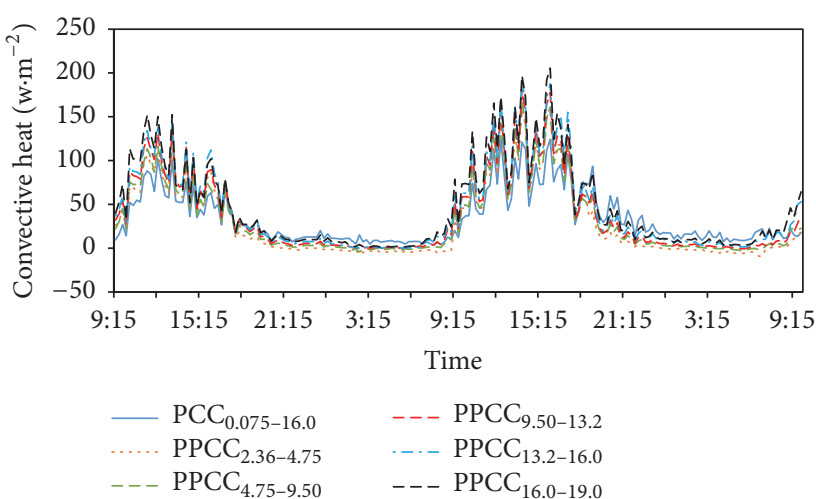

(a)

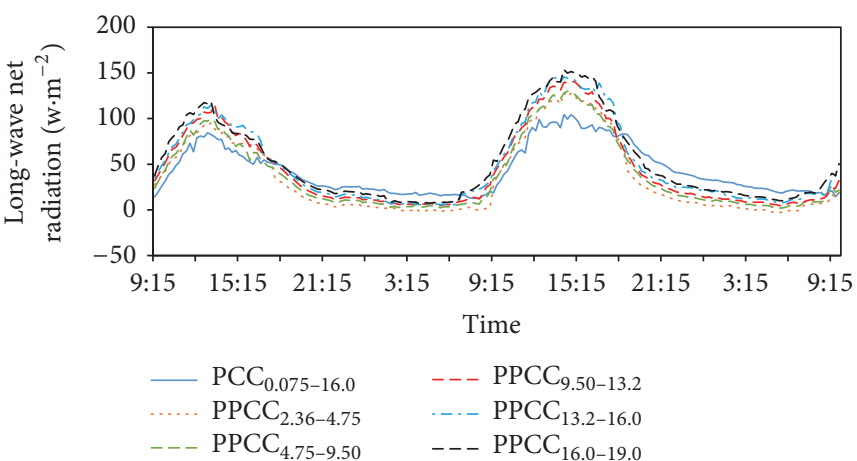

(b)

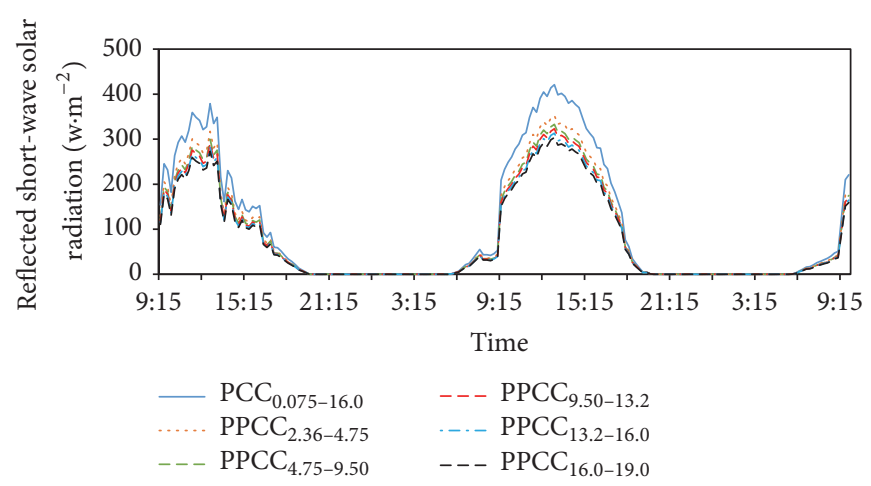

(c)

Figure 10: Surface heat flux of different concrete during $48 \mathrm{~h}$ in June 2016: (a) convective heat; (b) long-wave net radiation; (c) reflected short-wave solar radiation.

near-surface air temperature are little difference, although the surface temperatures of PPCC are higher than that of PCC in the daytime.

At night, the total output heat flux of concrete only relates to the convective heat flux and the long-wave net radiation in the nighttime because there is no solar radiation. The total output heat flux of all kinds of concrete decreases sharply. Taking PCC $_{0.075-16.0}$ and PPCC $_{16.0-19.0}$ as examples, the average of total output heat flux during the nighttime of the two kinds of concrete is $17.5 \%$ and $11.7 \%$ of that in the daytime. Additionally, the total output heat flux of PCC is obviously larger than those of PPCC in the nighttime. Taking the calculations of the total output heat flux in the nighttime of June 19 as an example, the average of total output heat flux of PPCC $_{2.36-4.75}$, PPCC $_{4.75-9.50}$, PPCC $_{9.50-13.2}$, PPCC $_{13.2-16.0}$, and $\mathrm{PPCC}_{16.0-19.0}$ decreases by $86.0 \%, 68.6 \%, 58.6 \%, 43.0 \%$, and $33.3 \%$ compared with $56.0 \mathrm{~W} / \mathrm{m}^{2}$ of $\mathrm{PCC}_{0.075-16.0}$, which shows that PPCC has less effect on the outside air temperature compared with the PCC at night. This can also explain from the view of heat output why the near-surface air temperature 


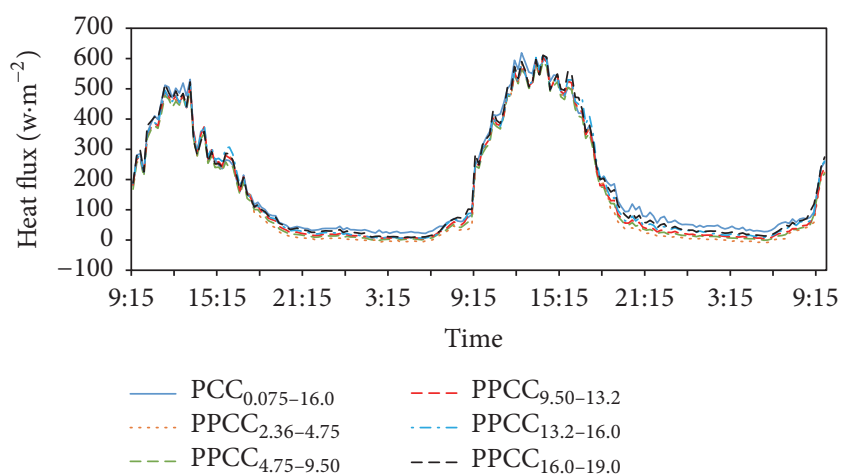

FIGURE 11: Total output heat flux of surface of different concrete during $48 \mathrm{~h}$ in June 2016.

above PPCC is generally lower than that above PCC after the specimens are covered by the box.

The total output heat flux in the daytime and nighttime is considered comprehensively; compared with PCC, PPCC contributes to mitigating the heating effect of pavement on the near-surface air.

\section{Conclusions}

The thermal parameters of PPCC, such as albedo, thermal conductivity, specific heat capacity, emissivity, and coefficient of thermal storage, are quite different to those of PCC. The main conclusions in this paper were drawn as follows by contrast experiments and calculation in hot weather.

(1) The PPCC has higher temperature in the sunny daytime and lower temperature in the nighttime and larger temperature gradient than the PCC. The surface and internal temperatures of the PPCC rise faster in the sunny daytime and decrease also faster in the nighttime than those of the PCC.

(2) Different concrete types have different influence on near-surface temperature. After the concrete specimens being exposed to the same solar radiation to heat up and then covered with boxes, the near-surface air temperatures of the PPCC are higher in a short period of the beginning and then are lower than those of the PCC.

(3) The total output heat flux of PPCC is slightly smaller than that of PCC during the day and is significantly smaller at night. PPCC could contribute to reducing the heating effect of pavement on the near-surface air.

\section{Competing Interests}

The authors declare that they have no competing interests.

\section{Acknowledgments}

This work was funded by Ministry of Science and Technology of China (2014BAG05B04). This project was also supported by the Special Fund for Basic Scientific Research of
Central College, Chang'an University, China (310821153308, 310821153202).

\section{References}

[1] A. K. Chandrappa and K. P. Biligiri, "Pervious concrete as a sustainable pavement material-research findings and future prospects: a state-of-the-art review," Construction and Building Materials, vol. 111, pp. 262-274, 2016.

[2] A. Yukari, Development of Pervious Concrete, University of Technology, Sydney, Australia, 2009.

[3] B. J. Wardynski, R. J. Winston, and W. F. Hunt, "Internal water storage enhances exfiltration and thermal load reduction from permeable pavement in the North Carolina mountains," Journal of Environmental Engineering, vol. 139, no. 2, pp. 187-195, 2012.

[4] J. Mullaney and T. Lucke, "Practical review of pervious pavement designs," Clean-Soil, Air, Water, vol. 42, no. 2, pp. 111-124, 2014.

[5] J. J. Chang, W. Yeih, T. J. Chung, and R. Huang, "Properties of pervious concrete made with electric arc furnace slag and alkaliactivated slag cement," Construction and Building Materials, vol. 109, pp. 34-40, 2016.

[6] M. Santamouris, "Using cool pavements as a mitigation strategy to fight urban heat island\&A review of the actual developments," Renewable and Sustainable Energy Reviews, vol. 26, pp. 224-240, 2013.

[7] H. Li, J. T. Harvey, T. Holland, and M. Kayhanian, “The use of reflective and permeable pavements as a potential practice for heat island mitigation and stormwater management," Environmental Research Letters, vol. 8, no. 1, pp. 15-23, 2013.

[8] J. Gui, P. E. Phelan, K. E. Kaloush, and J. S. Golden, "Impact of pavement thermophysical properties on surface temperatures," Journal of Materials in Civil Engineering, vol. 19, no. 8, pp. 683690, 2007.

[9] A. Hassn, M. Aboufoul, Y. Wu, A. Dawson, and A. Garcia, "Effect of air voids content on thermal properties of asphalt mixtures," Construction and Building Materials, vol. 115, pp. 327$335,2016$.

[10] L. Haselbach, M. Boyer, J. T. Kevern, and V. R. Schaefer, "Cyclic heat island impacts on traditional versus pervious concrete pavement systems," Transportation Research Record, no. 2240, pp. 107-115, 2011.

[11] R. Zhang, G. Jiang, and J. Liang, "The albedo of pervious cement concrete linearly decreases with porosity," Advances in Materials Science and Engineering, vol. 2015, Article ID 746592, 5 pages, 2015.

[12] J. T. Kevern, L. Haselbach, and V. R. Schaefer, "Hot weather comparative heat balances in pervious concrete and impervious concrete pavement systems," Journal of Heat Island Institute International, vol. 7, no. 2, 2012.

[13] R. S. Benrazavi, K. Binti Dola, N. Ujang, and N. Sadat Benrazavi, "Effect of pavement materials on surface temperatures in tropical environment," Sustainable Cities and Society, vol. 22, pp. 94-103, 2016.

[14] K. K. Guan, "Surface and ambient air temperatures associated with different ground material: a case study at the University of California, Berkeley," Environmental Science, vol. 196, pp. 1-14, 2011.

[15] T.-P. Lin, Y.-F. Ho, and Y.-S. Huang, "Seasonal effect of pavement on outdoor thermal environments in subtropical Taiwan," Building and Environment, vol. 42, no. 12, pp. 4124-4131, 2007. 
[16] A. H. Rosenfeld, H. Akbari, J. J. Romm, and M. Pomerantz, "Cool communities: strategies for heat island mitigation and smog reduction," Energy and Buildings, vol. 28, no. 1, pp. 51-62, 1998.

[17] Y. Qin and J. E. Hiller, "Understanding pavement-surface energy balance and its implications on cool pavement development," Energy and Buildings, vol. 85, pp. 389-399, 2014.

[18] T. Nakayama and T. Fujita, "Cooling effect of water-holding pavements made of new materials on water and heat budgets in urban areas," Landscape and Urban Planning, vol. 96, no. 2, pp. 57-67, 2010.

[19] J. J. Muñoz-Criollo, P. J. Cleall, and S. W. Rees, "Factors influencing collection performance of near surface interseasonal ground energy collection and storage systems," Geomechanics for Energy and the Environment, vol. 6, pp. 45-57, 2016.

[20] Y. Qin, "A review on the development of cool pavements to mitigate urban heat island effect," Renewable and Sustainable Energy Reviews, vol. 52, pp. 445-459, 2015. 

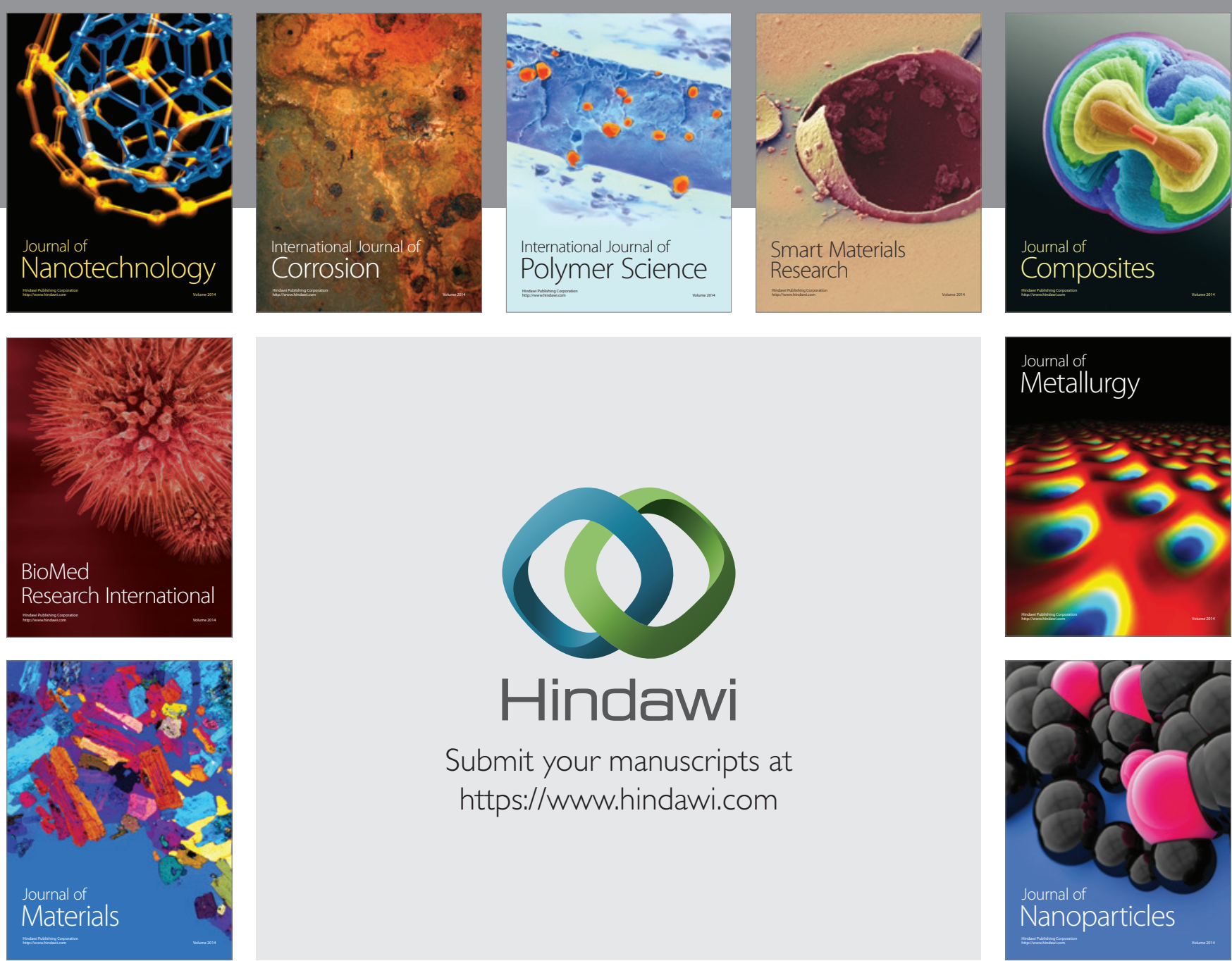

\section{Hindawi}

Submit your manuscripts at

https://www.hindawi.com

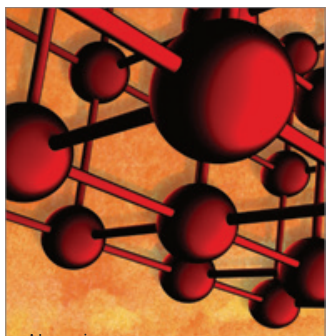

Materials Science and Engineering
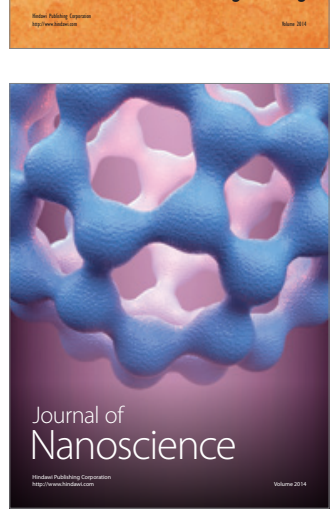
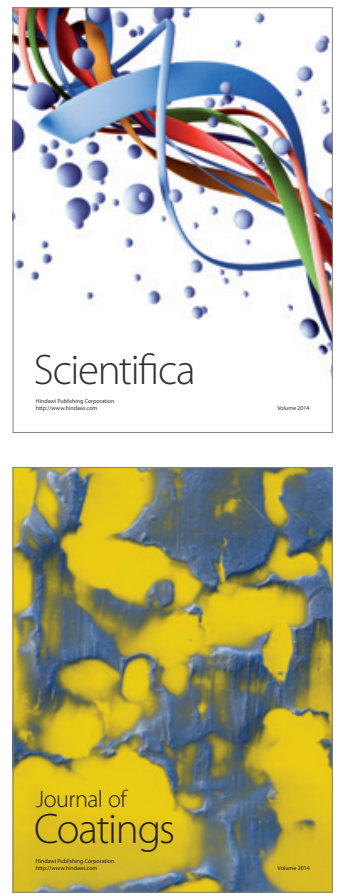
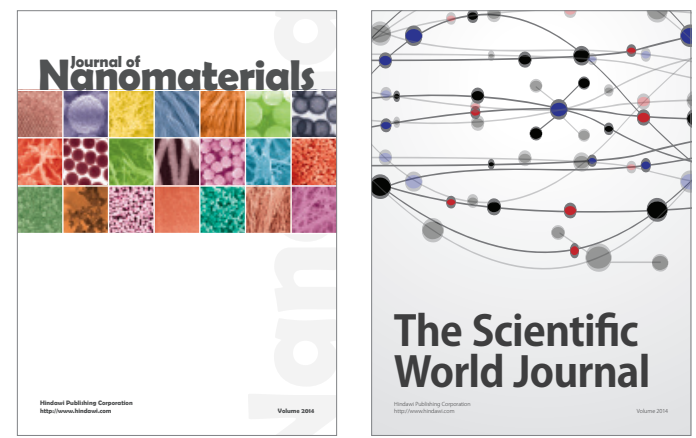

The Scientific World Journal
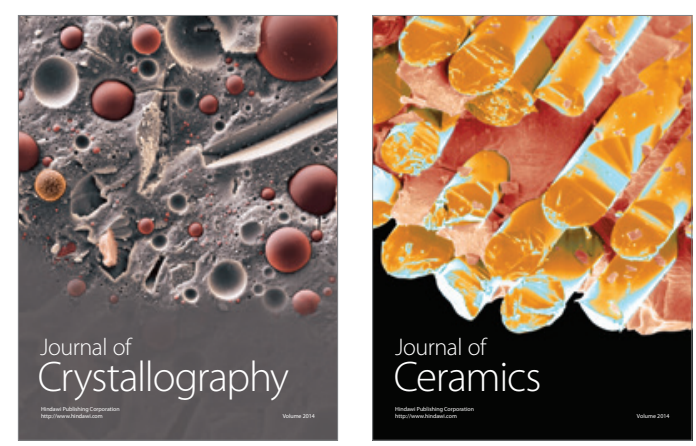
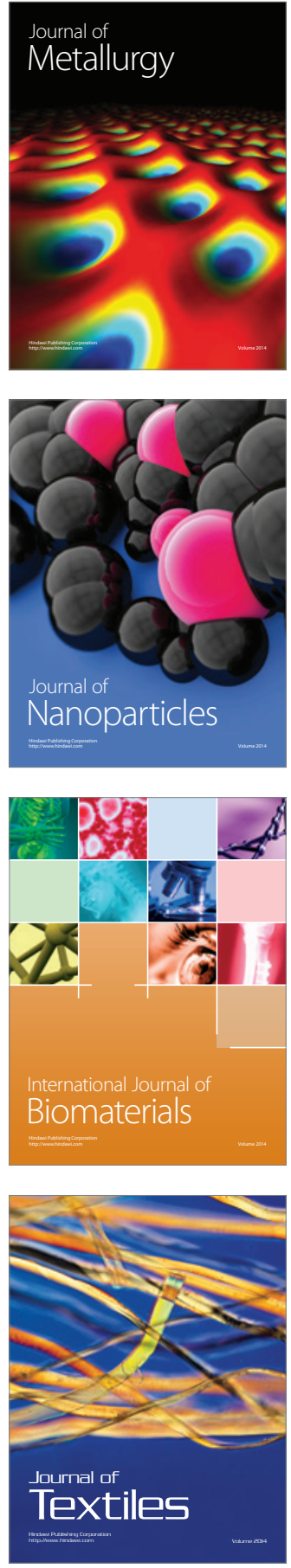